\title{
Validation of a Novel, Non-Invasive System for Autonomic Profiling in Healthy Volunteers
}

\author{
Agostino Ingraldi \\ Thomas Jefferson University, agostino.ingraldi@jefferson.edu \\ Behzad B. Pavri \\ Thomas Jefferson University, behzad.pavri@jefferson.edu \\ Himanshu Patel \\ Thomas Jefferson University, Himanshu.Patel@mail.tju.edu \\ Sammy Zakaria \\ Thomas Jefferson University, sammy.zakaria@jefferson.edu \\ Reginald T. Ho \\ Thomas Jefferson University, reginald.ho@iefferson.edu \\ Follow this and additional works at: https: $7 / j d c$.jefferson.edu/tmf \\ Part of the Neurology Commons

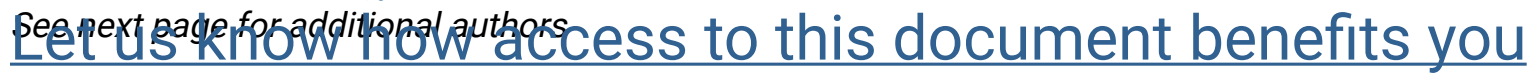

\section{Recommended Citation}

Ingraldi, Agostino; Pavri, Behzad B.; Patel, Himanshu; Zakaria, Sammy; Ho, Reginald T.; and Greenspon, Arnold J. (2003) "Validation of a Novel, Non-Invasive System for Autonomic Profiling in Healthy Volunteers," The Medicine Forum: Vol. 4 , Article 11.

DOI: https://doi.org/10.29046/TMF.004.1.003

Available at: https://jdc.jefferson.edu/tmf/vol4/iss1/11

This Article is brought to you for free and open access by the Jefferson Digital Commons. The Jefferson Digital Commons is a service of Thomas Jefferson University's Center for Teaching and Learning (CTL). The Commons is a showcase for Jefferson books and journals, peer-reviewed scholarly publications, unique historical collections from the University archives, and teaching tools. The Jefferson Digital Commons allows researchers and interested readers anywhere in the world to learn about and keep up to date with Jefferson scholarship. This article has been accepted for inclusion in The Medicine Forum by an authorized administrator of the Jefferson Digital Commons. For more information, please contact: JeffersonDigitalCommons@jefferson.edu. 


\section{Validation of a Novel, Non-Invasive System for Autonomic Profiling in Healthy}

Volunteers

\section{Authors}

Agostino Ingraldi, Behzad B. Pavri, Himanshu Patel, Sammy Zakaria, Reginald T. Ho, and Arnold J. Greenspon 


\section{Validation Of A Novel, Non-Invasive System \\ For Autonomic Profiling In Healthy Volunteers}

Agostino Ingraldi, MD, Thomas Jefferson University Hospital, Behzad B. Pavri, MD, Himanshu Patel, MD, Sammy Zakaria, MD, Reginald T. Ho, MD, Arnold J. Greenspon, MD, Thomas Jefferson University Hospital

Noninvasive profiling of the autonomic nervous system has been shown to have prognostic value in patients with myocardial infarction, CHF and diabetes. The ANSAR system (ANX 3.0, Philadelphia, PA) is a new commercially available system that utilizes respiratory rate, $\mathrm{HR}$ and $\mathrm{BP}$ to assess on-going sympathovagal modulation during various maneuvers known to evoke autonomic perturbations. Instead of using conventional Fast Fourier Transform for frequency domain analysis, a Continuous Wavelet Transform (CWT) is used to generate numerical and graphical data. The system calculates Low Frequency Area (LFA, analogous to LF Power) and Respiratory Frequency Area (RFA, analogous to High Frequency Power.) A time domain index (pNN50) is also calculated. We independently tested the ability of the ANSAR system to detect sympathovagal modulation during: (1) Isometric Handgrip (IHG), a maneuver known to result in sympathetic activation, and
(2) Deep Breathing (DB), a maneuver known to increase vagal modulation. We studied 15 healthy volunteers, aged $44.9 \pm 14.9$ yrs (range 25-63 yrs) during IHG (33\% of maximal contraction for 3 minutes or to point of fatigue) and during metronome DB (6 breaths/min.) A $4 \mathrm{~min}$ baseline (BL) period was allowed between maneuvers. Testing was performed in the post-absorptive state between the hours of 7:00 and 9:00 AM. Results are shown in the table below. We conclude that the ANSAR ANX 3.0 system accurately identified the sympathetic surge known to occur with IHG, as evidenced by increased HR, DBP and LFA/RFA ratio. The system also identified the vagal increase that occurred with DB, as evidenced by increased RFA and pNN50. This study validates the CWT methodology, and may allow the ANSAR system to become a clinically useful tool for autonomic profiling in various pathophysiologic states.

\begin{tabular}{l|l|l|l|l|l}
\hline Variable & BL & IHG & p (BL vs. IHG $)$ & DB & p (BL vs. DB) \\
\hline HR $(\mathbf{b p m})$ & $71.8 \pm 6.1$ & $84.3 \pm 7.4$ & $<0.001$ & $69.9 \pm 6.4$ & NS \\
\hline DBP $(\mathbf{m m ~ H g})$ & $73.7 \pm 9.0$ & $90.4 \pm 12.4$ & $<0.001$ & $70.3 \pm 7.0$ & NS \\
\hline LFA/RFA & $1.53 \pm 1.1$ & $3.2 \pm 5.0$ & 0.03 & $0.9 \pm 1.2$ & NS \\
\hline RFA & $4.17 \pm 1.0$ & $1.87 \pm 1.9$ & NS & $25.1 \pm 25.1$ & 0.006 \\
\hline pNN50 & $12 \pm 16.6$ & $4.5 \pm 5.6$ & NS & $30.5 \pm 19.0$ & 0.009 \\
\hline
\end{tabular}

$\mathrm{DBP}=$ diastolic blood pressure; $\mathrm{LFA}=$ low frequency area; $\mathrm{RFA}=$ respiratory frequency area; $\mathrm{pNN} 50=$ percentage of $\mathrm{RR}$ intervals that varied by $\geq 50 \mathrm{~ms} ; \mathrm{BL}=$ Baseline; $\mathrm{IHG}=$ Isometric Handgrip; DB=Deep Breathing. 